\title{
On the Practical Significance of the Psychological Theory of Vocational Education
}

\author{
Huayao $\mathrm{Xu}$ \\ Handan Polytechnic College \\ Handan,056001, China
}

\begin{abstract}
Psychological quality of students is an important part of overall quality. The reform of vocational education teaching psychology will comprehensively improve the overall quality of students, psychological characteristics of higher vocational education determines the ways and means of teaching psychology. Conducting psychology-teaching reform needs to respond appropriately in accordance with the overall training objectives of higher vocational education.
\end{abstract}

Keywords- Teaching Reform; Psychological Quality; Educational Theory; Practice Teaching

\section{INTRODUCTION}

Our higher education has exceeded elite education, entered the popular era, which has accounted for more than half of the vocational colleges of universities, a large number of vocational colleges are upgraded from the previous establishment of colleges. Some are from the previous Colleges and specialized colleges, and some are the newly established vocational schools. The number of vocational colleges and the number of students in higher education has been more than half. Vocational students mainly from three aspects: First, after students attend college admission, this is now a major general vocational college's student; the second is the organization of college admissions exam class students; the third is in the admission exams Vocational students. Sources are from the student, the student will need to go through in order to test the theory as the main form, in order to become college students, enrolled students from the college entrance examination scores in the entrance examination is generally not very good, generally in the specialist stalls admission. Admitted students from exams, exam test scores are generally not very good. From college class admitted candidates whose general theory classes participated in the test scores of students with the same. Students are from sources we can see that the students look at the overall higher category "Language and Mathematics" aspects of intelligence is not their strong suit. Vocational College Students come from different sources, there are also some differences between them, Cape High students have better theoretical basis, learning ability is relatively strong. It has relatively good study habits. Recruiting students is the theoretical foundation in general; they have good hands-on skills. Five-year and vocational high school students in the theory and practice of skills are needed for further development.

\section{PSYCHOLOGICALTEACHING CHARACTERISTICS OF HIGHER VOCATIONAL EDUCATION}

In March 1998,the first National College teaching sessionis held in Wuhan, twenty-first century Chinese universities were to foster solid foundation, broad knowledge, ability, and the general requirements of high-quality senior specialized talents. Chinese university personnel training have requirements for the $21 \mathrm{st}$ century; we must have "knowledge", but also a "capacity", but also have the knowledge and ability to make full quality. These three aspects to be organically integrated in a person's body. "CPC Central Committee and State Council is on deepening education reform, and comprehensively promotes quality education," issued June 13, 1999 pointed out: "to promote quality education training to adapt to the new socialist modernization requirements of the twenty-first century." And it Said: "The implementation of quality education is fully implement the Party's education policy, in order to improve the quality as the fundamental purpose, to cultivate the students' innovative spirit and practical ability to focus, to create ideals, morality, culture, morality and intelligence discipline and other body-round development of socialist builders and successors". It also pointed out: "it is to promote quality education for the needs of modernization, the world and the future, to make educated adhere to the study of science and culture and to strengthen the unity of ideological training. It is to adhere to the study of books of knowledge and social practice of unity, to adhere to realize their own value and services reunification of the people, to adhere to lofty ideals of unity and hard work carried out. "Thus, the quality of talent is a very broad concept connotation, it should include at least the cultural quality of personnel and training as production, construction, management and service line personnel should have some basic qualities, which includes the will, mental capacity cooperative ability, ethics and professional conduct and other so-called "critical capabilities." More vocational education training objectives will determine their courses of training plans and objectives: it must be "competency center" in order to cultivate technical skills and the basic quality of the main line to build the teaching system, practice teaching should account for a large ratio. Psychology is no exception; it must comply with the overall planning of higher vocational education, focusing on capacity building, strengthening the practical teaching. 


\section{EDUCATIONAL PSYCHOLOGY}

Psychological theory tells us, motivation is directly promoting students an internal motivation to learn, strict requirements for students, promote the spirit of hard study, can promote learning, but a truly lasting power of their own dynamic learning interest is from students and the resulting curiosity. For example, in answer to the purpose of learning a foreign language, some students said to be subject to parental pressure, as well as students said learning a foreign language is in order to pass the exam. This narrow learning objective will determine the low level of their motivation, learning the lack of consciousness and the necessary perseverance. This part of the people is to carry out targeted ideological work; it enlightens them with reason, and emotionally moving. Both from improving their quality and realizing the value of life ambitious goal is to educate them, but also improve individual skills and enhance the competitiveness of individual employment needs and other practical perspective to inspire them. Once you understand the significance of language learning and responsibilities, motivation significantlyenhanced conscientiously attentive Class and the after-school homework, difficulties also showed greater selfcontrol and indomitable spirit.

By means of psychological theory, you can put all the inherent characteristics of seemingly complex language skills, and the links between them and their development revealed law, which provides a scientific basis for the development of targeted intensive training methods. Due to emphasis basic skills and skills in accordance with the laws of its own development-targeted training, the students mostly in a short period have a better grasp of the skills and the training effect has been greatly improved.

\section{BASIC IDEAS OF MODERN COGNITIVE PSYCHOLOGY THEORIES}

The core idea of modern cognitive psychology is that what is an information processing system, the system is characterized by symbolic form of things in the external environment, or during the operation, it is said the internal and external environment, the process can operate the system on their own processing. For this basic theoretical framework of cognitive psychology, the study of human information processing system processes a variety of laws, characteristics and nature of the information.Thus, it can deepen our understanding of human perception, memory, thinking and other knowledge activities and understanding, and then use the results to better play in this respect the human ability to understand the world. Modern cognitive psychology highlighted the study of human cognitive processes inside, the basic idea is also prominently reflected the will of the human brain and the computer analogy, the human brain as a computer information processing system is similar to the fundamental point of view. Information Processing famous psychologist Emanuel and Simon (Newell \& Si-mon) believes that humans and computers and information processing systems generally have a common characteristic, that is, they are composed of several parts receptors, processor, memory and effector systems a processing system. Wherein the memory system is the information storage means, and it need some time information stored therein. The system will extract the information stored in symbolic form the required processing time information; processing is a set of information processing, such as searching for information, it can compare and evaluate the current information or extract information from the memory system to determine basic information processing sequences or procedures. Processing of the entire system is marked with the symbol structure. We can say that the human brain and the computer have an input, output, storage mechanisms and procedures for processing based on certain symbolic operating system. The basic idea of cognitive psychology also implies a fundamental view: human information processing using certain cognitive strategies. That is, the human information processing often has to use previous knowledge, experience, and the use of certain methods to process information. This in itself is an active, selective activity, emphasizing the initiative of human cognitive activities. Thus, cognitive psychology is very stressed in the problem solving process of human cognitive strategy.

\section{REVELATION EDUCATIONAL PSYCHOLOGY THEORY OF EDUCATION}

\section{A. Choose Teaching Methods Based on Cognitive}

There is some puzzling phenomenon in the field of teaching. Before school, students have a natural way of learning to master a large number of complex knowledge. For example, students simply are listening and speaking because they are living in a society, they learned while using the lips, tongue, breath and sound to communicate with people. This task is very complex; the learning process was a breeze. In contrast, relatively little knowledge of student learning in schools has been difficult. Constructivist interpretation is that this difference is artificial, inappropriate teaching methods led to it, classroom learning is not natural. If the learning process in schools and in the outside world are using learning programs, students will be able to go to school as easily as before, quickly mastering the skills. Constructivists believe that learning from the students' own activities, all part of the process of learning are developed, along with the growth of the students that gradually expanded. In the classroom, as long as there is a variety of ways for students to enter a natural process of knowledge, students' interest in learning and problem-solving skills can be further developed. Evolutionary psychology education put forward different views, students do not need to enter the school and they will be able to learn to speak, identify objects, remember the characteristics of a friend, because these are the primary biological knowledge, it is information vital to human survival and reproduction. Natural selection makes humans have evolved a modular domain-specific cognitive system to quickly deal with plain areas particularly important information, and generate corresponding 
behavioral strategies. At the same time, humans have evolved in the field of general cognitive system, or general intelligence, to ensure that human learning plasticity in response to changes in the social and ecological environment. General intelligence is considered the key to the ability to obtain a secondary biological effect. Reading and writing, math, science and principles of knowledge and skills of written language are a recent invention, the ability to belong to the field of bio-secondary, is any species evolved skills that cannot match, the student must receive formal education to master. From this point of understanding, academic learning for students and teachers are daunting task, those who advocate happy and relaxed learning remarks failed to fully recognize the limitations of the human cognitive system, and underestimated the difficulty of learning.

\section{B. Accelerate the Transformation of Educational Ideas and Concepts of Education}

Schools should carry out deep changes in thought and discussion of education educational concepts, improve social awareness of vocational education, establish a comprehensive strengthening of the students who are learning the subject, strengthen the cultivation of students' innovative ability, and implementindividualized education. They should actively encourage and foster the development of the concept of individual strengths of students, gradually change teaching limited to "teacher-centered, classroomcentered, with books as the center" of the situation, and effectively take the educational development of teaching and research, the combination of theory and practice road.According to Academy training program, they should vigorously promote the teaching content, teaching methods and curriculum system reform; and strengthen practice, reasonable arrangements for class, give students more autonomy time to promote students' personality development and innovation ability. It should be based on knowledge transfer, focusing on making ability, outstanding quality improvement, financial knowledge, ability and quality in one.

\section{Develop Practical Teaching Practice Plan andHighlight the Practice Teaching}

"The ability should be in the center of Higher Vocational Education, in order to cultivate technical skills and the basic quality of the main line to build the teaching system, it accounts for a large proportion of teaching practice in training model ", which is one of the basic characteristics of higher vocational education. Contribute to the formation and development of the practice of teaching students 'vocational skills; application of theory is to consolidate students learn to help students acquire new knowledge jobs work; help develop students' creative thinking skills and creative abilities. At the same time, the practice of teaching also helps college "double Teachers" team building. Therefore, the College should develop an implementation plan carefully practice teaching, well-organized every practice teaching, to enable students to master the job effectively working knowledge and job skills.

\section{CONCLUSIONS}

Putting forward the Educational psychology theory is very timely, but it caused widespread concern and attention. The significance of the construction process and the status of the student body prone to over-emphasize the leading role of teachers despise, even ignored signs of lecture-style teaching methods deviate from the principle of exclusion of blindly different guidance based on different types of knowledge. Evolutionary educational psychology is rooted in the study of teaching on the cognitive development of a deeper understanding through evolutionary psychology perspective, which can be found constructivist understanding of learning and teaching deviation, avoidance will only apply to a specific range teaching methods to promote question of the concept of universal education. Evolutionary psychology education division of the primary and secondary areas of knowledge and skills in the field are to help teachers better understand the motives and the way students learn, and for the different stages and content of student learning, we should choose appropriate teaching methods. This theory of educational research opens up new perspectives and expands the research field of educational psychology.

\section{References}

[1] Yang Fan, Yang Yaju.Contemporary psychological theories of education and Its Implications for Foreign Language Teaching [J] Northern Forum, 2003,02: 121-123.

[2] Liu Hong.Theory and practice of educational psychology at the University English Teaching [J] Education Forum, 2014,44: 179-181.

[3] Wang Jianzhong and Li Xiufang. Psychology Higher Vocational Education Reform Study [J] Hebei Vocational and Technical College, 2001,02: 23-25.

[4] Zhu Yunzhi.Positive evolutionary psychology theory of education Education [J] Educational Theory and Practice, 2012,21: 34-36.

[5] Xia Yuling. On the memory psychology Cited For Technical Implications on English Vocabulary Teaching in Vocational College [J] Jilin College of Education (mid), 2012,09: 117-119.

[6] Lu Xiaoli, KeJianhua.Revelation educational psychology theory on English Teaching [J] theoretical magazine, 2008,06: 126-127.

[7] Zhao Dongsheng. Revelation Theory of Multiple Intelligences on Higher Vocational Education [J] Education Forum, 2006,20: 11-14.

[8] Li Yuanjian.Revelation constructivist learning theory on Higher Vocational Education [J] Jinan Vocational College, 2009,02: 11-14. 